\title{
Article \\ Some New Oscillation Criteria of Even-Order Quasi-Linear Delay Differential Equations with Neutral Term
}

\author{
Rongrong Guo ${ }^{1, *,+} \mathbb{C}$, Qingdao Huang ${ }^{1,+}\left(\mathbb{C}\right.$ and Qingmin Liu ${ }^{2,+}$ \\ 1 Mathematics College, Jilin University, Changchun 130012, China; Huangqd@jlu.edu.cn \\ 2 School of Control Science and Engineering, Shandong University, Jinan 250061, China; \\ lqmin20201011@163.com \\ * Correspondence: guorr16@mails.jlu.edu.cn \\ + These authors contributed equally to this work.
}

check for updates

Citation: Guo, R.; Huang, Q.; Liu, Q. Some New Oscillation Criteria of Even-Order Quasi-Linear Delay Differential Equations with Neutral Term. Mathematics 2021, 9, 2074. https://doi.org/10.3390/math9172074

Academic Editors: Blanka Baculíková and Christopher Goodrich

Received: 30 May 2021

Accepted: 23 August 2021

Published: 27 August 2021

Publisher's Note: MDPI stays neutral with regard to jurisdictional claims in published maps and institutional affiliations.

Copyright: (c) 2021 by the authors. Licensee MDPI, Basel, Switzerland. This article is an open access article distributed under the terms and conditions of the Creative Commons Attribution (CC BY) license (https:/ / creativecommons.org/licenses/by/ $4.0 /)$.

\begin{abstract}
The neutral delay differential equations have many applications in the natural sciences, technology, and population dynamics. In this paper, we establish several new oscillation criteria for a kind of even-order quasi-linear neutral delay differential equations. Comparing our results with those in the literature, our criteria solve more general delay differential equations with neutral type, and our results expand the range of neutral term coefficient. Some examples are given to illustrate our conclusions.
\end{abstract}

Keywords: delay differential equation; quasi-linear; neutral; oscillation

\section{Introduction}

Up to now, many academics have made essential contributions to the delay differential equations, because such equations have various applications in natural science and social science [1-5]. For example, when studying the London-Yorke model of measles transmission [6], some scholars considered the following delay equation

$$
\dot{y}(t)=\rho(t) y(t)[y(t-12)-y(t-14)-2 \sigma]+\sigma,
$$

where $\sigma>0$.

In the study of lossless transmission lines in electrical networks, the following equation [7].

$$
\dot{y}(t)-a \dot{y}(t-\sigma)=f(y(t), \dot{y}(t-\sigma))
$$

is derived.

Since the delay differential equation is obviously different from the ordinary differential equation, the method of studying ordinary differential equation cannot be used to that. Thus, researchers have focused attention on the qualitative theory of delay differential equations, where the oscillation and asymptotic behavior of the equation is an important branch.

Over the last several years, many researchers considered the oscillation of the nonlinear delay differential equation as follows:

$$
\left(a(t)\left(\chi^{(n-1)}(t)\right)^{\eta}\right)^{\prime}+c(t) f(y(h(t)))=0
$$

where $t \geq t_{0}, \chi(t)=y(t)+b(t) y(g(t)), a \in C^{1}\left(\left[t_{0}, \infty\right),(0, \infty)\right), b \in C^{n}\left(\left[t_{0}, \infty\right),(0, \infty)\right)$, $c \in C\left(\left[t_{0}, \infty\right),(0, \infty)\right), g \in C^{n}\left(\left[t_{0}, \infty\right), \mathbb{R}\right)$ is one-one mapping, $h \in C\left(\left[t_{0}, \infty\right), \mathbb{R}\right), g(t) \leq$ $t, h(t) \leq t, f(-v)=-f(v)$ and $\eta \in S=\left\{i \mid i=\frac{2 m+1}{2 k+1}, m, k \in N^{*}\right\}$. The neutral differential equation refers to a type of differential equation with a delay in the highest derivative. In the Equation (3), $g(t), h(t) \leq t$, and they are the delay terms. 
Here, a function $y \in C^{n}\left(\left[t_{y}, \infty\right), \mathbb{R}\right)$ is a solution of (3) if it has the property $a(t)\left(\chi^{(n-1)}(t)\right)^{\eta}$ $\in C^{1}\left(\left[t_{y}, \infty\right), \mathbb{R}\right)$ and satisfies Equation (3) on $\left(t_{y}, \infty\right)$, where $t_{y} \geq t_{0}$. We only considered the proper solution of (3) which satisfies $\sup \{|y(t)|: t \geq \mathfrak{T}\}>0$ for all $\mathfrak{T} \geq t_{y}$.

A proper solution of (3) is oscillatory if it has infinitely many zeros on $\left[t_{y}, \infty\right)$. That is, for any $t_{1} \geq t_{y}$, there exists $t_{2} \geq t_{1}$, s.t. $y\left(t_{2}\right)=0$. Otherwise, it is called non-oscillatory. Equation (3) is oscillatory if all its proper solutions are oscillatory.

In the case where $n=2$, authors [8-16] investigated the quasi-linear equation as follows:

$$
\left(a(t)\left(\chi^{\prime}(t)\right)^{\eta}\right)^{\prime}+c(t) y^{\eta}(h(t))=0,
$$

where $\eta \in S$. They $[10,13]$ studied the oscillation criteria of $(4)$ for $b(t) \in[0,1)$. In $[9,12]$, academics derived some oscillation criteria for $\eta=1, b(t) \in\left[0, b_{0}\right]$ and $b_{0}<\infty$.

In $[14,15]$, authors discussed the oscillation behavior of the Emden-Fowler equation

$$
\left(a(t)\left(\chi^{\prime}(t)\right)^{\eta}\right)^{\prime}+c(t) y^{\theta}(h(t))=0,
$$

where $\eta, \theta \in S$. In [14], T. X. Li et al. mainly concerned oscillation behavior of (5) when $b(t) \in\left[0, b_{0}\right]$ and $b_{0}<\infty$ holds. In [15], R. P. Agarwal et al. considered that when $b(t) \in[0,1)$ holds.

Expanding this approach to all higher-order equations attracts the attention of more and more researchers. B. Baculíková et al. [17] discussed the following quasi-linear equation by using the comparison principles and Riccati transformation:

$$
\left(\left(\chi^{(n-1)}(t)\right)^{\eta}\right)^{\prime}+c(t) y^{\eta}(h(t))=0
$$

where $n$ is even, $\eta \geq 1, b(t) \in\left[0, b_{0}\right]$ and $b_{0}<\infty$.

If $\eta=1$, then Equation (6) becomes

$$
\chi^{(n)}(t)+c(t) y(h(t))=0
$$

They [18-21] studied the oscillation of (7) under the condition $b(t) \in[0,1)$. In [22-24], authors investigated the oscillatory solutions of (7) where $b(t) \in\left[0, b_{0}\right]$ and $b_{0}<\infty$.

Based on the above results of previous scholars, in this article, we are concerned with the following quasi-linear neutral delay differential equations of the form (i.e., Equation (3) when $\left.f(v)=v^{\eta}\right)$

$$
\left(a(t)\left(\chi^{(n-1)}(t)\right)^{\eta}\right)^{\prime}+c(t) y^{\eta}(h(t))=0
$$

where $n$ is even. The study of quasi-linear differential equations has numerous applications, such as in the study of $p$-Laplace equations, porous medium problems, chemotaxis models, and so forth; see, e.g., the papers [25-27] for more details.

We establish some oscillation criteria of (8) by using the Riccati transformation technique and comparison method. Compared with the second-order results of [4,8-16], we extend Equations (4) and (5) to Equation (8), where $n$ is even. For the results of [17-24,28-34], we get the oscillation criteria of the more general equations. In other word, $a(t)$ may not be $1, \eta \in S$ and $b(t)$ is not only bounded, but also can be unbounded. Therefore, we complement and extend upon some results reported in literature. At the end of this paper, some examples are provided to exhibit our conclusions.

\section{Auxiliary Lemmas}

Throughout this paper, we will analyze the following situations of $a(t), b(t), g(t)$, and $h(t)$ :

Hypothesis 1 (H1). $a(t)>0, a^{\prime}(t) \geq 0, \kappa(t):=\int_{t_{0}}^{t} a^{-\frac{1}{\eta}}(s) d s, \lim _{t \rightarrow \infty} \kappa(t)=\infty$; 
Hypothesis 2 (H2). $0 \leq b(t)<1$;

Hypothesis 3 (H3). $0 \leq b(t) \leq b_{0}<\infty$;

Hypothesis $4(\mathbf{H} 4) . b(t)>1, h(t) \leq g(t)$;

Hypothesis $\mathbf{5}$ (H5). $g^{\prime}(t) \geq g_{0}>0, h^{\prime}(t)>0$.

Before starting our major criteria, the following lemmas are needed.

Lemma 1 ([35]). Let $f \in C^{n}\left(\left[t_{0}, \infty\right),(0, \infty)\right)$. If $f^{(n)}(t)$ is eventually of one sign for all large $t$, then there exist $a t_{x} \geq t_{0}$ and an integer $l, 0 \leq l \leq n$ with $n+l$ even for $f^{(n)}(t) \geq 0$, or $n+l$ odd for $f^{(n)}(t) \leq 0$, such that

$$
\begin{aligned}
& l>0 \text { yields } f^{(k)}>0 \text { for } t \geq t_{x}, k=0,1, \ldots, l-1, \text { and } \\
& l \leq n-1 \text { yields }(-1)^{l+k} f^{(k)}(t)>0 \text { for } t \geq t_{x}, k=l, l+1, \ldots, n-1 .
\end{aligned}
$$

Lemma 2 ([36], Lemma 2.2.3). If $f$ is as in Lemma 1, $f^{(n)}(t) f^{(n-1)}(t) \leq 0$ for $t \geq t_{x}$, and $\lim _{t \rightarrow \infty} f(t) \neq 0$, then for every constant $\lambda \in(0,1)$, there exists $t_{\lambda} \in\left[t_{x}, \infty\right)$, such that

$$
f(t) \geq \frac{\lambda}{(n-1) !} t^{n-1}\left|f^{(n-1)}(t)\right|
$$

holds on $\left[t_{\lambda}, \infty\right)$.

Lemma 3 ([37], Lemma 2.3). Let $g(u)=a u-b u^{\frac{\beta+1}{\beta}}$, where $a$ and $b$ are positive constants, $\beta \in S$. Then, $g$ attains its maximum value on $\Re^{+}$at $u^{*}=\left(\frac{\beta a}{(\beta+1) b}\right)^{\beta}$ and

$$
\max _{u \in \Re^{+}} g=g\left(u^{*}\right)=\frac{\beta^{\beta}}{(\beta+1)^{\beta+1}} \frac{a^{\beta+1}}{b^{\beta}} .
$$

Lemma 4 ([38], Lemmas 1 and 2). Assume that $\alpha \in(0, \infty)$ and $x_{1} \geq 0$ and $x_{2} \geq 0$. Then,

$$
x_{1}^{\alpha}+x_{2}^{\alpha} \geq \frac{1}{2^{\alpha-1}}\left(x_{1}+x_{2}\right)^{\alpha} \quad \text { if } \quad \alpha \geq 1,
$$

and

$$
x_{1}^{\alpha}+x_{2}^{\alpha} \geq\left(x_{1}+x_{2}\right)^{\alpha} \quad \text { if } \quad 0<\alpha<1
$$

Lemma 5 ([39]). If a function $f$ satisfies $f^{(i)}>0, i=1,2, \ldots, k$ and $f^{(k+1)} \leq 0$, then, for every $\operatorname{lin}(0,1), \frac{f(t)}{f^{\prime}(t)} \geq \frac{l t}{k}$.

Lemma 6. Let $y(t)$ be an eventually positive solution of (8). If (H1) and the hypotheses of Lemma 1 hold, then there exist $t_{1} \geq t_{0}$, such that:

$$
\chi(t)>0, \quad \chi^{\prime}(t)>0, \quad \chi^{(n-1)}(t)>0 \quad \text { and } \quad \chi^{(n)}(t)<0, \quad t \geq t_{1} .
$$

More precisely, $\chi(t)$ has the following two cases for $t \geq t_{1}$ :

(I) For $l>1, \chi(t)>0, \chi^{\prime}(t)>0, \chi^{\prime \prime}(t)>0, \chi^{(n-1)}(t)>0, \chi^{(n)}(t)<0$;

(II) For $l=1, \chi(t)>0, \chi^{(i)}(t)>0, \chi^{(i+1)}(t)<0, \chi^{(n-1)}(t)>0, \chi^{(n)}(t)<0$, where $l, i \in L=\{j \mid j=2 m+1 \leq n-3, m \in N\}$.

Proof. The proof of (11) is similar to that of ([29], Lemma 2.3), and so we omit it. Furthermore, we can conclude that case (I) and (II) hold. 


\section{Main Results}

Now, let us begin our main criteria. For simplicity, we use the following symbols:

$$
\begin{gathered}
\left(\Gamma^{\prime}(t)\right)_{+}:=\max \left(0, \Gamma^{\prime}(t)\right), \quad\left(\varphi^{\prime}(t)\right)_{+}:=\max \left(0, \varphi^{\prime}(t)\right), \\
B(t):=c(t)(1-b(h(t)))^{\eta}, \quad B^{*}(t):=\left(\int_{t}^{\infty} B(s) d s\right)^{\frac{1}{\eta}}, \\
\Theta_{1}(t):=\frac{\delta}{(n-1) !} t^{n-1}, \quad \Theta_{2}(t):=\frac{\delta}{(n-2) !} t^{n-2}, \\
H(t):=\frac{a(t)\left(\Gamma^{\prime}(t)\right)_{+}^{\eta+1}}{(\eta+1)^{\eta+1}\left(\Gamma(t) \Theta_{2}(h(t)) h^{\prime}(t)\right)^{\eta}}, \\
H^{*}(t):=\frac{a(t) \Gamma^{\prime}(t)_{+}^{\eta+1}}{(\eta+1)^{\eta+1}\left(\Gamma(t) \Theta_{2}\left(g^{-1}(h(t))\right) \zeta(t) h^{\prime}(t)\right)^{\eta}}, \\
M(t):=\frac{1}{b\left(g^{-1}(t)\right)}\left(1-\frac{\left(g^{-1}\left(g^{-1}(t)\right)\right)^{\frac{n-1}{l}}}{\left(g^{-1}(t)\right)^{\frac{n-1}{l}} b\left(g^{-1}\left(g^{-1}(t)\right)\right)}\right) \\
M^{*}(t):=\left(\int_{t}^{\infty} c(s) M^{\eta}(h(s)) d s\right)^{\frac{1}{\eta}},
\end{gathered}
$$

where $\Gamma, \varphi \in C^{1}\left(\left[t_{0}, \infty\right),(0, \infty)\right), \delta, l \in(0,1), \zeta(t)=\left.\left(g^{-1}\right)^{\prime}(v)\right|_{v=h(t)}$ and $g^{-1}$ is the inverse function of $g$.

Theorem 1. If $\eta>0,(H 1),(H 3),(H 5)$ and

$$
\int_{t_{0}}^{\infty} C(t) d t=\infty
$$

hold, where $C(t)=\min \{c(t), c(g(t))\}$, then (8) is oscillatory.

Proof. Suppose towards a contradiction that (8) is not oscillatory, and let $y$ be such a solution of (8). Then, we can clearly assume that $y>0$ eventually positive. That is, $y(t)>0, y(g(t))>0, y(h(t))>0$ for $t \in\left[t_{1}, \infty\right)$, where $t_{1} \geq t_{0}$. By $\eta>0$, we need to divide into two situations to discuss, that is $\eta \geq 1$ and $0<\eta<1$.

When $\eta \geq 1$ is satisfied, owing to Lemma 6, we have that (11) holds. According to Equation (8), we obtain

$$
\left(a(t)\left(\chi^{(n-1)}(t)\right)^{\eta}\right)^{\prime}=-c(t) y^{\eta}(h(t))<0, \quad t \geq t_{1} .
$$

Thus, $a(t)\left(\chi^{(n-1)}(t)\right)^{\eta}$ is not increasing for $t \geq t_{1}$. Let $\Phi(t)=a(t)\left(\chi^{(n-1)}(t)\right)^{\eta}$, $\Psi(t)=y^{\eta}(h(t))$. By the definition of $\chi$ and (13), we get

$$
(\Phi(t))^{\prime}+c(t) \Psi(t)+\frac{b_{0}^{\eta}}{g^{\prime}(t)}(\Phi(g(t)))^{\prime}+b_{0}^{\eta} c(g(t)) \Psi(g(t)) \leq 0,
$$

which leads to

$$
(\Phi(t))^{\prime}+\frac{b_{0}^{\eta}}{g_{0}}(\Phi(g(t)))^{\prime}+C(t)\left(\Psi(t)+b_{0}^{\eta} \Psi(g(t))\right) \leq 0 .
$$


According to Lemma 4 and (H3), we have

$$
(\Phi(t))^{\prime}+\frac{b_{0}^{\eta}}{g_{0}}(\Phi(g(t)))^{\prime}+\frac{1}{2^{\eta-1}} C(t) \chi^{\eta}(h(t)) \leq 0 .
$$

Integrating (15) from $t_{1}$ to $t$, we obtain

$$
\frac{1}{2^{\eta-1}} \int_{t_{1}}^{t} C(s) \chi^{\eta}(h(s)) d s \leq \Phi\left(t_{1}\right)-\Phi(t)+\frac{b_{0}^{\eta}}{g_{0}}\left(\Phi\left(g\left(t_{1}\right)\right)-\Phi(g(t))\right) .
$$

By $\chi^{\prime}(t)>0$ on $\left[t_{1}, \infty\right)$, we get $\chi(h(t))>\alpha>0$ on $\left[t_{1}, \infty\right)$. By virtue of (H1), (11) and (13), we know that $\Phi(t)>0, \Phi^{\prime}(t)<0$, and so $\Phi(t)$ is bounded. Thus, the right of (16) is bounded, contrary to (12).

If $0<\eta<1$, the argument is analogous to that in the above discussion, so is omitted. This completes the proof.

Corollary 1. Let the hypotheses of Theorem 1 hold. If the following inequality

$$
\left(\Phi(t)+\frac{b_{0}^{\eta}}{g_{0}} \Phi(g(t))\right)^{\prime}+\frac{1}{2^{\eta-1}} \frac{C(t)}{a(h(t))} \Theta_{1}^{\eta}(h(t)) \Phi(h(t)) \leq 0
$$

has no eventually positive solution, then (8) is oscillatory.

Proof. Similar to the proof of Theorem 1, we have (11), (15) and $\lim _{t \rightarrow \infty} \chi(t) \neq 0$. Thus, by Lemma 2 , there exists $t_{2} \geq t_{1}$, such that

$$
\chi(t) \geq \Theta_{1}(t) \chi^{(n-1)}(t), \quad t \geq t_{2}
$$

That achieves

$$
\left(\Phi(t)+\frac{b_{0}^{\eta}}{g_{0}} \Phi(g(t))\right)^{\prime}+\frac{1}{2^{\eta-1}} \frac{C(t)}{a(h(t))} \Theta_{1}^{\eta}(h(t)) \Phi(h(t)) \leq 0 .
$$

It is straightforward to know that $\Phi(t)$ is positive and satisfies (19). The proof is complete.

Corollary 2. If the hypotheses of Theorem 1 holds, and

$$
\left(\Phi(t)+\frac{b_{0}^{\eta}}{g_{0}} \Phi(g(t))\right)^{\prime}+\frac{C(t)}{a(h(t))} \Theta_{1}^{\eta}(h(t)) \Phi(h(t)) \leq 0
$$

has no eventually positive solution, then (8) is oscillatory.

Theorem 2. Let $n \geq 4$ be even and (H1), (H2), (H5) hold. If there exist $\Gamma \in C^{1}\left(\left[t_{0}, \infty\right),(0, \infty)\right)$ and $\varphi \in C^{1}\left(\left[t_{0}, \infty\right),(0, \infty)\right)$, such that

$$
\int_{t_{1}}^{\infty}[\Gamma(t) B(t)-H(t)] d t=\infty
$$

and

$$
\int_{t_{1}}^{\infty}\left[\varphi(t) \int_{t}^{\infty}(\vartheta-t)^{n-4} \frac{B^{*}(\vartheta)}{(n-4) ! a^{\frac{1}{\eta}}(\vartheta)} d \vartheta-\frac{\left(\varphi^{\prime}(t)\right)_{+}^{2}}{4 \varphi(t) h^{\prime}(t)}\right] d t=\infty,
$$

then (8) is oscillatory. 
Proof. Suppose that (8) is not oscillatory. Without loss of generality, assume that $y$ is an eventually positive solution of (8). That means $y(t)>0, y(g(t))>0, y(h(t))>0$ on $t \in\left[t_{1}, \infty\right)$. By the assumptions and Lemma $6, \chi$ satisfies case $(I)$ or case $(I I)$.

First, we consider case $(I)$. Then, $\lim _{t \rightarrow \infty} \chi^{\prime}(t) \neq 0$. From that and Lemma 2, we achieve

$$
\chi^{\prime}(t) \geq \Theta_{2}(t) \chi^{(n-1)}(t) .
$$

By $h(t) \leq t$ and the fact that $\chi^{(n-1)}(t)$ is not increasing, we obtain

$$
\frac{\chi^{\prime}(h(t))}{\chi^{(n-1)}(t)} \geq \frac{\chi^{\prime}(h(t))}{\chi^{(n-1)}(h(t))} \geq \Theta_{2}(h(t)) .
$$

Owing to $\chi^{\prime}>0$ and the definition of $\chi$, we have

$$
y(h(t)) \geq(1-b(h(t))) \chi(h(t))
$$

Let

$$
\mu(t):=\Gamma(t) \frac{a(t)\left(\chi^{(n-1)}(t)\right)^{\eta}}{\chi^{\eta}(h(t))}, \quad t \geq t_{1} .
$$

Thus, $\mu(t)>0$ on $\left[t_{1}, \infty\right)$ and set

$$
d(t):=\frac{\left(\Gamma^{\prime}(t)\right)_{+}}{\Gamma(t)}, \quad e(t):=\frac{\eta h^{\prime}(t) \Theta_{2}(h(t))}{(\Gamma(t) a(t))^{\frac{1}{\eta}}} .
$$

Then

$$
\mu^{\prime}(t) \leq-\Gamma(t) B(t)+d(t) \mu(t)-e(t) \mu^{\frac{\eta+1}{\eta}}(t) .
$$

By Lemma 3, we get

$$
d(t) \mu(t)-e(t) \mu^{\frac{\eta+1}{\eta}}(t) \leq H(t) .
$$

Thus,

$$
\mu^{\prime}(t) \leq-\Gamma(t) B(t)+H(t) .
$$

This yields

$$
\int_{t_{1}}^{r}[\Gamma(t) B(t)-H(t)] d t \leq \mu\left(t_{1}\right),
$$

for all large enough $r$, which contradicts (21).

For the case (II), according to (8) and (24), we achieve

$$
\left(a(t)\left(\chi^{(n-1)}(t)\right)^{\eta}\right)^{\prime}+B(t) \chi^{\eta}(h(t)) \leq 0, \quad t \geq t_{1} .
$$

Integrating (27) from $t$ to $\infty$, from $\chi^{\prime}(t)>0$ and (H5), we get

$$
-\chi^{(n-1)}(t)+\chi(h(t)) \frac{B^{*}(t)}{a^{\frac{1}{\eta}}(t)} \leq 0 .
$$

Integrating (28) from $t$ to $\infty$, we derive

$$
\chi^{(n-2)}(t)+\chi(h(t)) \int_{t}^{\infty} \frac{B^{*}(\vartheta)}{a^{\frac{1}{\eta}}(\vartheta)} d \vartheta \leq 0 . \quad t \geq t_{1} .
$$


Continuously, if we integrate (29) from $t$ to $\infty$ for all $(n-4)$ times we obtain

$$
\chi^{\prime \prime}(t)+\chi(h(t)) \int_{t}^{\infty} \frac{(\vartheta-t)^{n-4} B^{*}(\vartheta)}{(n-4) ! a^{\frac{1}{\eta}}(\vartheta)} d \vartheta \leq 0, \quad t \geq t_{1} .
$$

Now, let

$$
v(t):=\varphi(t) \frac{\chi^{\prime}(t)}{\chi(h(t))}, \quad t \geq t_{1} .
$$

It is easy to verify that $v(t)>0$ on $\left[t_{1}, \infty\right)$. Since $\chi^{\prime}$ is decreasing and $h(t) \leq t$, according to Lemma 3 , we get

$$
v^{\prime}(t) \leq-\varphi(t) \int_{t}^{\infty} \frac{(\vartheta-t)^{n-4} B^{*}(\vartheta)}{(n-4) ! a^{\frac{1}{\eta}}(\vartheta)} d \vartheta+\frac{\left(\varphi^{\prime}(t)\right)_{+}^{2}}{4 \varphi(t) h^{\prime}(t)} .
$$

This implies that

$$
\int_{t_{1}}^{r}\left[\varphi(t) \int_{t}^{\infty} \frac{(\vartheta-t)^{n-4} B^{*}(\vartheta)}{(n-4) ! a^{\frac{1}{\eta}}(\vartheta)} d \vartheta-\frac{\left(\varphi^{\prime}(t)\right)_{+}^{2}}{4 \varphi(t) h^{\prime}(t)}\right] d t \leq v\left(t_{1}\right)
$$

for any $r$ large enough. This contradicts our assumption (22), which completes the proof.

Theorem 3. Let $n \geq 4$ be even and (H1), (H4), (H5) hold. If there exist $\Gamma, \varphi \in C^{1}\left(\left[t_{0}, \infty\right),(0, \infty)\right)$ which satisfy

$$
\int_{t_{1}}^{\infty}\left[c(t) \Gamma(t) M^{\eta}(h(t))-H^{*}(t)\right] d t=\infty
$$

and

$$
\int_{t_{1}}^{\infty}\left[\varphi(t) \int_{t}^{\infty} \frac{(\vartheta-t)^{n-4} M^{*}(\vartheta)}{(n-4) ! a^{\frac{1}{\eta}}(\vartheta)} d \vartheta-\frac{\varphi^{\prime}(t)^{2}}{4 \varphi(t) h^{\prime}(t) \zeta(t)}\right] d t=\infty,
$$

then (8) is oscillatory.

Proof. Just as the proof of Theorem 2, by the above assumptions, $\chi$ satisfies either case $(I)$ or case $(I I)$.

Suppose that $(I)$ holds. By the definition of $\chi$ and (H4), we get

$$
y(t) \geq \frac{1}{b\left(g^{-1}(t)\right)}\left(\chi\left(g^{-1}(t)\right)-\frac{\chi\left(g^{-1}\left(g^{-1}(t)\right)\right)}{b\left(g^{-1}\left(g^{-1}(t)\right)\right)}\right) .
$$

According to Lemma 5, we obtain

$$
\frac{\chi(t)}{\chi^{\prime}(t)} \geq \frac{l t}{n-1}
$$

where $l \in(0,1)$, which leads to that $\frac{\chi(t)}{t^{\frac{n-1}{l}}}$ is non-increasing. By $g^{-1}(t) \leq g^{-1}\left(g^{-1}(t)\right)$ and (35), we derive

$$
y(t) \geq \chi\left(g^{-1}(t)\right) M(t)
$$

By (8) and (37), we gain

$$
\left(a(t)\left(\chi^{(n-1)}(t)\right)^{\eta}\right)^{\prime}+c(t) \chi^{\eta}\left(g^{-1}(h(t))\right) M^{\eta}(h(t)) \leq 0 .
$$

Then define

$$
\mu^{*}(t):=\Gamma(t) \frac{a(t)\left(\chi^{(n-1)}(t)\right)^{\eta}}{\chi^{\eta}\left(g^{-1}(h(t))\right)}, \quad t \geq t_{1}
$$


Since $\mu^{*}(t)>0$ on $\left[t_{1}, \infty\right)$, by (23) and Lemma 3, we have

$$
\left(\mu^{*}\right)^{\prime}(t) \leq-c(t) \Gamma(t) M^{\eta}(h(t))+H^{*}(t) .
$$

This yields

$$
\int_{t_{1}}^{r}\left[c(t) \Gamma(t) M^{\eta}(h(t))-H^{*}(t)\right] d t \leq \mu^{*}\left(t_{1}\right)
$$

for all large $r$, in contradiction with (33).

Then, assume that case (II) is true. Thus, we have that (38) holds. Integrating (38) from $t$ to $\infty$, by virtue of $\chi^{\prime}(t)>0$ and (H5), we obtain

$$
-\chi^{(n-1)}(t)+\chi\left(g^{-1}(h(t))\right) \frac{M^{*}(t)}{a^{\frac{1}{\eta}}(t)} \leq 0 .
$$

Integrating (41) from $t$ to $\infty$, we obtain

$$
\chi^{(n-2)}(t)+\chi\left(g^{-1}(h(t))\right) \int_{t}^{\infty} \frac{M^{*}(\vartheta)}{a^{\frac{1}{\eta}}(\vartheta)} d \vartheta \leq 0 . \quad t \geq t_{1} .
$$

Integrating (42) from $t$ to $\infty$ for $(n-4)$ times, we achieve

$$
\chi^{\prime \prime}(t)+\chi\left(g^{-1}(h(t))\right) \int_{t}^{\infty} \frac{(\vartheta-t)^{n-4} M^{*}(\vartheta)}{(n-4) ! a^{\frac{1}{\eta}}(\vartheta)} d \vartheta \leq 0, \quad t \geq t_{1} .
$$

Let

$$
v^{*}(t):=\varphi(t) \frac{\chi^{\prime}(t)}{\chi\left(g^{-1}(h(t))\right)}, \quad t \geq t_{1} .
$$

Then $v^{*}(t)>0$. Since $\chi^{\prime}(t)$ is decreasing, by (H4), (43) and Lemma 3, we get

$$
\left(v^{*}\right)^{\prime}(t) \leq-\varphi(t) \int_{t}^{\infty} \frac{(\vartheta-t)^{n-4} M^{*}(\vartheta)}{(n-4) ! a^{\frac{1}{\eta}}(\vartheta)} d \vartheta+\frac{\varphi^{\prime}(t)^{2}}{4 \varphi(t) h^{\prime}(t) \zeta(t)} .
$$

This implies that

$$
\int_{t_{1}}^{r}\left[\varphi(t) \int_{t}^{\infty} \frac{(\vartheta-t)^{n-4} M^{*}(\vartheta)}{(n-4) ! a^{\frac{1}{\eta}}(\vartheta)} d \vartheta-\frac{\varphi^{\prime}(t)^{2}}{4 \varphi(t) h^{\prime}(t) \zeta(t)}\right] d t \leq v^{*}\left(t_{1}\right)
$$

for all large $r$, which contradicts (34). The proof of the theorem is complete.

\section{Examples}

For $t \geq 1$, the following examples are given to verify our criteria.

\section{Example 1.}

$$
\left(e^{t}\left(\left(x(t)+3 x\left(\frac{t}{2}\right)\right)^{(3)}\right)^{3}\right)^{\prime}+\frac{1}{t} x^{3}\left(\frac{t}{3}\right)=0,
$$

where $n=4, a(t)=e^{t}, b(t)=3, \eta=3, c(t)=\frac{1}{t}, g(t)=\frac{t}{2}, h(t)=\frac{t}{3}$. Using Theorem 1, we know that $C(t)=c(t)=\frac{1}{t}$ and $\int_{1}^{\infty} \frac{1}{s} d s=\infty$. Thus, (45) is oscillatory.

\section{Example 2.}

$$
\left(e^{t}\left(\left(x(t)+\frac{1}{2} x\left(\frac{t}{3}\right)\right)^{(3)}\right)^{\frac{1}{5}}\right)^{\prime}+e^{t} x^{\frac{1}{5}}\left(\frac{t}{4}\right)=0,
$$


where $n=4, a(t)=e^{t}, b(t)=\frac{1}{2}, \eta=\frac{1}{5}, c(t)=e^{t}, g(t)=\frac{t}{3}, h(t)=\frac{t}{4}$. Using Theorem 1, we know that $C(t)=c(g(t))=e^{\frac{t}{3}}$ and $\int_{1}^{\infty} e^{\frac{s}{3}} d s=\infty$. Thus, (46) is oscillatory.

\section{Example 3.}

$$
\left(t\left(x(t)+\frac{1}{2} x\left(\frac{t}{2}\right)\right)^{(3)}\right)^{\prime}+\frac{c_{0}}{t^{3}} x\left(\frac{9 t}{10}\right)=0,
$$

where $n=4, a(t)=t, b(t)=\frac{1}{2}, \eta=1, c(t)=\frac{c_{0}}{t^{3}}, g(t)=\frac{t}{2}, h(t)=\frac{9 t}{10}$. Letting $\Gamma(t)=t^{2}$, $\varphi(t)=t, \delta=\frac{9^{3}-1}{9^{3}}$. Then,

$$
\begin{gathered}
B(t)=\frac{c_{0}}{2 t^{3}}, \\
H(t)=\frac{2000}{9^{3} \delta t} .
\end{gathered}
$$

Thus, $c_{0} \geq \frac{4000}{9^{3}-1} \approx 5.5$, then

$$
\begin{gathered}
\int_{t_{1}}^{\infty}\left(\frac{c_{0}}{2}-\frac{2000}{9^{3} \delta t}\right) t^{-1} d t \rightarrow \infty \text { as } \quad t \rightarrow \infty . \\
B^{*}(\vartheta)=\int_{\vartheta}^{\infty} \frac{c_{0}}{2} s^{-3} d s=\frac{c_{0}}{4} \vartheta^{-2} .
\end{gathered}
$$

Thus, $c_{0} \geq \frac{20}{9} \approx 2.2$, then

$$
\int_{t_{1}}^{\infty}\left(\frac{c_{0}}{8}-\frac{5}{18}\right) t^{-1} d t \rightarrow \infty \quad \text { as } \quad t \rightarrow \infty
$$

Thus, we can conclude that (47) is oscillatory if $c_{0} \geq \frac{4000}{9^{3}-1} \approx 5.5$ when using Theorem 2.

Remark 1. Using the criteria of Theorem 2, we can obtain the same estimation as that in Example 3.1 [23]. Further, the results of $[18-21,23]$ cannot solve (47) because of $a(t)=t$ and $\eta \in S$. Thus, our results complement and extend upon the results of previous papers on this topic.

\section{Example 4.}

$$
\left(t\left(x(t)+16 x\left(\frac{t}{2}\right)\right)^{(3)}\right)^{\prime}+\frac{c_{0}}{t^{3}} x\left(\frac{t}{3}\right)=0,
$$

where $n=4, a(t)=t, b(t)=16, \eta=1, c(t)=\frac{c_{0}}{t^{3}}, g(t)=\frac{t}{2}, h(t)=\frac{t}{3}, h(t)<g(t)$. Letting $\Gamma(t)=t^{2}, \varphi(t)=t, \delta=\frac{27 \times 8-1}{27 \times 8}, l=\frac{10^{4}-1}{10^{4}}$,

$$
\begin{aligned}
M^{\eta}(h(t))=\frac{1}{16}\left(1-\frac{2^{\frac{3}{l}}}{16}\right) & \approx \frac{1}{32} \text { as } l=\frac{10^{4}-1}{10^{4}} . \\
H^{*}(t) & =\frac{27}{4 \delta t} .
\end{aligned}
$$

Thus, if $c_{0} \geq \frac{27 \times 8}{\delta} \approx 217.1$, then (33) $\rightarrow \infty$.

$$
M^{*}(\vartheta)=\int_{\vartheta}^{\infty} \frac{c_{0}}{32} s^{-3} d s=\frac{c_{0}}{64} \vartheta^{-2} .
$$

Thus, if $c_{0} \geq \frac{3 \times 128}{8}=48,(34) \rightarrow \infty$. Thus, we know that (48) is oscillatory if $c_{0} \geq \frac{27 \times 8}{\delta} \approx$ 217.1 when using Theorem 3. 
Remark 2. Using the criteria of Theorem 3, we can get the same estimation as that in Example 3.2 [23]. Further, the results of [28-34] cannot solve (48) because of $a(t)=t, \eta>0$ and $b(t)>1$.

Remark 3. The results obtained in this article can be extended to the more general Equation (3) when assuming that $\frac{f(v)}{v^{\eta}} \geq q_{0}$ for all $v \neq 0$, where $q_{0}>0$ is a constant and the equation of the form

$$
\left(a(t)\left|\chi^{(n-1)}(t)\right|^{\eta-1} \chi^{(n-1)}(t)\right)^{\prime}+c(t)|y(h(t))|^{\eta-1} y(h(t))=0
$$

where $\eta>0$ is a constant.

Remark 4. In this article, the neutral term coefficient $b(t)$ not only can be bounded (i.e., $0<$ $b(t)<1$ ) but also can be unbounded (i.e., $b(t)>1$ ).

Author Contributions: Writing—original draft, R.G., Q.H. and Q.L. All authors contributed equally to this work. All authors have read and agreed to the published version of the manuscript.

Funding: This work is supported by the National Natural Science Foundation of Jilin province (20180101221JC).

Institutional Review Board Statement: Not applicable.

Informed Consent Statement: Not applicable.

Data Availability Statement: Not applicable.

Acknowledgments: The authors sincerely thank the reviewers and editors for their useful comments, which led to the improvement of the paper.

Conflicts of Interest: The authors declare no conflicts of interest.

\section{References}

1. Hale, J.K. Theory of Functional Differential Equations; Springer: New York, NY, USA, 1977.

2. Gyori, I.; Ladas, G. Oscillation Theory of Delay Differential Equations with Application; Oxford University Press: Oxford, UK, 1991.

3. Ou, C.H.; Wong, J.S.W. Oscillation and non-oscillation theorems for superlinear Emden-Fowler equations of the fourth-order. Ann. Mat. Pura Appl. 2004, 183, 25-43. [CrossRef]

4. Wong, J.S.W. On the generalized Emden-Fowler equation. SIAM Rev. 1975, 17, 339-360. [CrossRef]

5. Li, T.X.; Rogovchenko, Y.V. On the asympotic behavior of solutions to a class of third-order nonlinear neutral differential equations. Appl. Math. Lett. 2020, 105, 106293. [CrossRef]

6. London, W.P.; Yorke, J.A. Recurrent outbreaks of measles, chickenpox and mumps. Am. J. Epidemiol. 1973, 98, 453-468. [CrossRef] [PubMed]

7. Brayton, R.K. Nonlinear oscillations in a distributed network. Q. Appl. Math. 1967, 24, 289-301. [CrossRef]

8. Han, Z.L.; Li, T.X.; Sun, S.R.; Sun, Y.B. Remarks on the paper [Appl. Math. Comput. 207 (2009) 388-396]. Appl. Math. Comput. 2010, 215, 3998-4007. [CrossRef]

9. Baculíková, B.; Džurina, J. Oscillation theorems for second order neutral differential equations. Comput. Math. Appl. 2011, 61, 94-99. [CrossRef]

10. Grace, S.R.; Džurina, J.; Jadlovská, I.; Li, T.X. An improved approch for studying oscillation of second-order neutral delay differential equations. J. Inequalities Appl. 2018, 2018, 193. [CrossRef]

11. Džurina, J.; Grace, S.R.; Jadlovská, I.; Li, T.X. Oscillation criteria for second-order Emden-Fowler delay differential equations with a sublinear neutral term. Math. Nachrichten 2020, 293, 910-922. [CrossRef]

12. Li, T.X.; Rogovchenko, Y.V. Oscillation criteria for second-order superlinear Emden-Fowler neutral differential equations. Monatshefte Math. 2017, 184, 489-500. [CrossRef]

13. Agarwal, R.P.; Zhang, C.H.; Li, T.X. Some remarks on oscillation of second order neutral differential equations. Appl. Math. Comput. 2016, 274, 178-181. [CrossRef]

14. Li, T.X.; Rogovchenko, Y.V. Oscillation of second-order neutral differential equations. Math. Nachrichten 2015, 288, 1150-1162. [CrossRef]

15. Agarwal, R.P.; Bohner, M.; Li, T.X.; Zhang, C.H. Oscillation of second-order Emden—Fowler neutral delay differential equations. Ann. Mat. Pura Appl. 2014, 193, 1861-1875. [CrossRef]

16. Li, T.X.; Rogovchenko, Y.V.; Zhang, C.H. Oscillation of second-order neutral differential equations. Funkc. Ekvacioj 2013, 56, 111-120. [CrossRef] 
17. Baculíková, B.; Džurina, J.; Li, T.X. Oscillation results for even-order quasi-linear neutral functional differential equations. Electron. J. Differ. Equ. 2011, 2011, 1-9.

18. Karpuz, B.; Öcalan, Ö.; Öztürk, S. Comparison theorems on the oscillation and asymptotic behaviour of higher-order neutral differential equations. Glasg. Math. J. Trust. 2010, 52, 107-114. [CrossRef]

19. Zafer, A. Oscillation criteria for even order neutral differential equations. Appl. Math. Lett. 1998, 11, 21-25. [CrossRef]

20. Zhang, Q.X.; Yan, J.R.; Gao, L. Oscillation behavior of even-order nonlinear neutral differential equations with variable coefficients. Comput. Math. Appl. 2010, 59, 426-430. [CrossRef]

21. Zhang, Q.X.; Yan, J.R. Oscillation behavior of even order neutral differential equations with variable coefficients. Appl. Math. Lett. 2006, 19, 1202-1206. [CrossRef]

22. Li, T.X.; Han, Z.L.; Zhao, P.; Sun, S.R. Oscillation of even-order neutral delay differential equations. Adv. Differ. Equ. 2010, 2010, 184180. [CrossRef]

23. Agarwal, R.P.; Bohner, M.; Li, T.X.; Zhang, C.H. A new approach in the study of oscillatory behavior of even-order neutral delay differential equations. Appl. Math. Comput. 2013, 225, 787-794. [CrossRef]

24. Li, T.X.; Rogovchenko, Y.V. Oscillation criteria for even-order neutral differential equations. Appl. Math. Lett. 2016, 61, 35-41. [CrossRef]

25. Bohner, M.; Li, T.X.; Oscillation of second-order $p$-Laplace dynamic equations with a nonpositive neutral coefficient. Appl. Math. Lett. 2014, 37, 72-76. [CrossRef]

26. Li, T.X.; Pintus, N.; Viglialoro, G. Properties of solutions to porous medium problems with different sources and boundary conditions. Z. Angew. Math. Phys. 2019, 70, 86. [CrossRef]

27. Li, T.X.; Viglialoro, G. Boundedness for a nonlocal reaction chemotaxis model even in the attraction-dominated regime. Differ. Integral Equ. 2021, 34, 315-336.

28. Baculíková, B.; Džurina, J. Oscillation theorems for higher order neutral differential equations. Appl. Math. Comput. 2012, 219, 3769-3778. [CrossRef]

29. Meng, F.W.; Xu, R. Oscillation criteria for certain even order quasi-linear neutral differential equations with deviating arguments. Appl. Math. Comput. 2007, 190, 458-464. [CrossRef]

30. Sun, Y.B.; Han, Z.L.; Sun, S.R.; Zhang, C. Oscillation criteria for even order nonlinear neutral differential equations. Electron. J. Qual. Theory Differ. Equ. 2012, 30, 1-12. [CrossRef]

31. Zhang, C.H.; Li, T.X.; Sun, B.; Thandapani, E. On the oscillation of higher-order half-linear delay differential equations. Appl. Math. Lett. 2011, 24, 1618-1621. [CrossRef]

32. Zhang, C.H.; Agarwal, R.P.; Bohner, M.; Li, T.X. New results for oscillatory behavior of even-order half-linear delay differential equations. Appl. Math. Lett. 2013, 26, 179-183. [CrossRef]

33. Agarwal, R.P.; Bohner, M.; Li, T.X.; Zhang, C.H. Even-order half-linear advanced differential equations: improved criteria in oscillatory and asymptopic properties. Appl. Math. Comput. 2015, 266, 481-490. [CrossRef]

34. Li, T.X.; Rogovchenko, Y.V. On asymptopic behavior of solutions to higher-order sublinear Emden-Fowler delay differential equations. Appl. Math. Lett. 2017, 67, 53-59. [CrossRef]

35. Philos, C.G. A new criterion for the oscillatory and asymptotic behavior of delay differential equations. Bull. Acad. Pol. Sci. Sér. Sci. Math. 1981, 39, 61-64.

36. Agarwal, R.P.; Grace, S.R.; O'Regan, D. Oscillation Theory for Difference and Functional Differential Equations; Kluwer Academic Publishers: Dordrecht, The Netherlands, 2000.

37. Zhang, S.Y.; Wang, Q.R. Oscillation of second-order nonlinear neutral dynamic equations on time scales. Appl. Math. Comput. 2010, 216, 2837-2848. [CrossRef]

38. Thandapani, E.; Li, T.X. On the oscillation of third-order quasi-linear neutral functional differential equations. Arch. Math. (BRNO) Tomus 2011, 47, 181-199.

39. Kiguradze, I.T.; Chanturia, T.A. Asymptotic Properties of Solutions of Nonautonomous Ordinary Differential Equations; Translated from the 1985 Russian Original; Kluwer Academic: Dordrecht, The Netherlands, 1993. 